\title{
IoT based Anti- Poaching Alarm System for Valuable Trees
}

\author{
Pooja Baraddi \\ Dept. of Information Science \\ SKSVMACET, Lakshmeshwar, India \\ Nanda Hanchinal \\ Dept. of Information Science \\ SKSVMACET, Lakshmeshwar, India
}

\author{
Ritika Jadhav \\ Dept. of Information Science \\ SKSVMACET, Lakshmeshwar, India \\ Shushma \\ Dept. of Information Science \\ SKSVMACET, Lakshmeshwar, India
}

\author{
Ms. Rajeshwari Banni \\ Dept. of Information Science \\ Assistant Prof. SKSVMACET, Lakshmeshwar, India
}

\begin{abstract}
For many days we are reading in newspaper about smuggling of trees like Sandal, Sagwan etc. These trees are very costly as well as less available in the world. In India The jungles of Karnataka and Tamilnadu, the notorious smuggler "Virrappan did the smuggling of such trees for many years. To restrict such smuggling of and save the forests around the globe some preventive measures need to be developed. Because of huge amount of money involved in selling of such trees lot of incidents are happening of cutting of trees. In this context we are supposed to provide a protection to the trees which can be used to restrict this smuggling. The purpose of this project is to save valuable trees which have high demand in market like teak, sandalwood, etc.
\end{abstract}

\section{INTRODUCTION}

Today internet application development demand is very high. So IOT is a major technology by which we can produce various useful internet applications.

Nowadays there are many internet about smuggling of trees like Sandal, Sagwan etc. These trees are very costly and meagre. They are used in the medical sciences, cosmetics. To restrict their smuggling and to save forests around the globe some preventive measures need to be deployed. We have developed a system which can be used to restrict smuggling. The design system uses three sensors tilt sensor, temperature sensor and sound sensor. For tilt sensor and sound sensor buzzer is activated and for temperature sensor water pump is activated.

The implementation of a real time, wireless sensor network and data logging system which will be a sophisticated and a cheap modern technology to make monitoring more robust, effective and feasible. WSN is a most emerging technology, widely used in many industrial applications such as monitoring, maintenance, security and control application, specific in remote monitoring applications etc. In forest areas, WSN are widely used for fire detection in forest, to detect poaching of trees, for environmental monitoring, etc.

\section{LITERATURE SURVEY}

[1] IOT Based Anti-Poaching Alarm System for trees in Forest using Wireless Sensor Networks: In this paper a system which can be used to restrict smuggling. The design system uses three sensors tilt sensor, temperature sensor, sound sensor. Data generated from these sensors is continuously monitored with the aid of Blynk App. With respect to the sensors, their output devices are activated through relay switch. For tilt sensor and sound sensor a buzzer is activated and for temperature sensor a water pump is activated. Generated data is stored in Blynk Server over the Wi-Fi module. Forest officials are notified when any event occurs so that appropriate action can be taken.

[2] Design of a WSN node forest trees against poaching This paper propose a microcontroller based antipoaching system employing WSN technology, which is capable of detecting theft by monitoring the vibrations produced by the cutting of trees/ branches using a 3 axis MEMS accelerometer. WSN is widely used technology in remote monitoring applications. Due to nature disaster some trees may fallen and create some sounds for that purpose they are using GPS module for continuous monitoring of trees location.

[3] Forest Monitoring System Using Wireless Sensor Network: This project presents a system for monitoring forest and its vicinity based on IOT based wireless sensor network technology. This system need to be able to accurately monitor forest cover and quality is crucial to understanding the costs of deforestation. This project is an attempt to prevent forest mishaps, the intrusion of animals in the surrounding forest areas, illegal activities in the forest by using wireless sensor technology and [4] eliminating manual power $\mathrm{t}$ the highest possible extent.

\section{PROPOSED SYSTEM}

The main idea is to design a portable wireless sensor node which will be a part of a Wireless Sensor Network. This system will consist of two modules one involving sensors and controller module which will be at tree spot another one is android phone. This is an IOT based project, in case of tilt sensor and the buzzer turns on when tree bends and for temperature sensor water pump is turned on in case of forest fire through relay switch. 


\section{SYSTEM ARCHITECTURE}

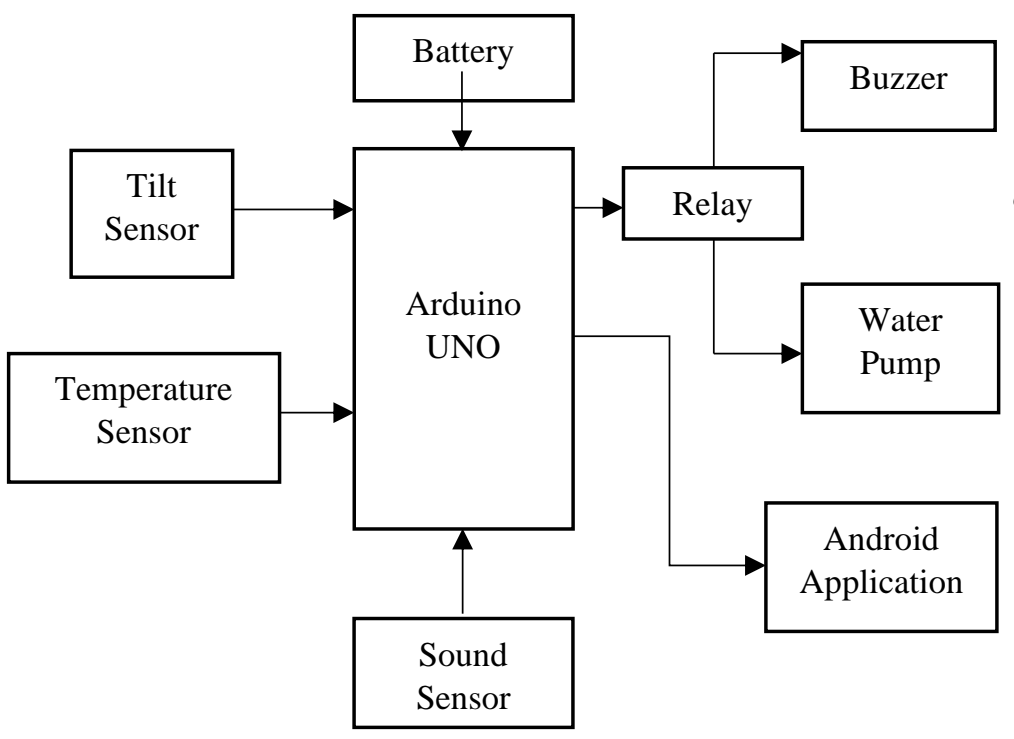

Fig 4.1 Architecture of Anti-Poaching Alarm System

Module 1- Arduino UNO

The Arduino UNO is an open-source microcontroller board based on the Microchip ATmega328P microcontroller and developed by Arduino.cc. The board is equipped with sets of digital and analog input/output pins that may be interfaced to various expansion boards and other circuits.

Module 2- Tilt Sensor

Tilt sensors are used to measure angle within a limited range of motion tilt sensors are called as inclinometers because the Sensors just produce a signal but inclinometers produce both readout and a signal. These devices produce an electrical signal that varies with an angular movement.

Module 3- Temperature Sensor

It is a device which is designed specifically to measure the hotness or coldness of an object or in an environment. We have used LM35 Temperature Sensor. It can measure temperature more correctly compare with thermistor. The operating temperature range is from $40^{\circ} \mathrm{C}$. The LM35 has an output voltage that is proportional to the Celsius temperature.

\section{Module 4- Sound Sensor}

The Sound sensor is a board that combines a microphone and some processing circuit. This module is used to detect the intensity of sound. When the sensor detects a sound, it processes an output voltage signal voltage is sent to a microcontroller then performs necessary processing.

Module 5- Relay Switch

High voltage electronic devices can be controlled using relays. A Relay is a switch which is electrically operated by an electromagnet. The electromagnet gets activated with a low voltage, for example 5 volts from a microcontroller and it pulls a contact to make or break a high voltage circuit. One of the most advantage is you can do with an Arduino is controlling higher voltage (120-241V) devices like fans, light, heaters, and other household appliances.

Module 6- Android Application
An android app is a software application running on the Android platform. Because the Android platform is built for mobile devices, a typical Android app is designed for a smartphone or a tablet PC running on the Android.

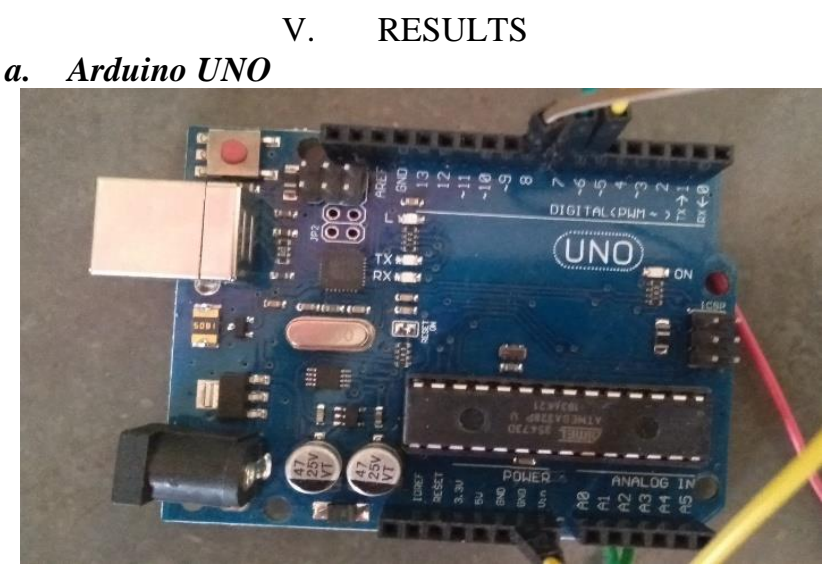

Fig 5.1 Arduino UNO

Arduino is an open-source electronics platform based on easy-to-use hardware and software. Arduino boards are able to read inputs and turn it into an output.

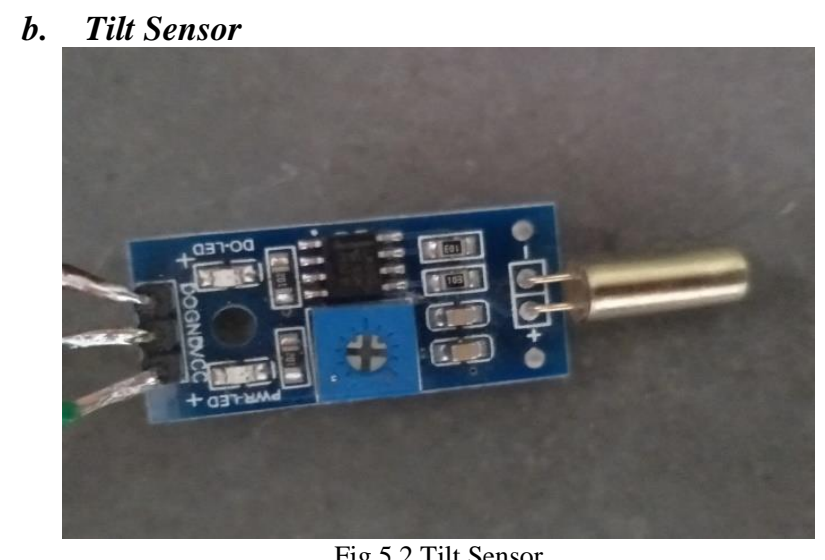

Fig 5.2 Tilt Sensor

Tilt sensor measures the tilting position with reference to gravity and are used in numerous applications. This enable the easy direction of orientation or inclination.

\section{d. Temperature Sensor}

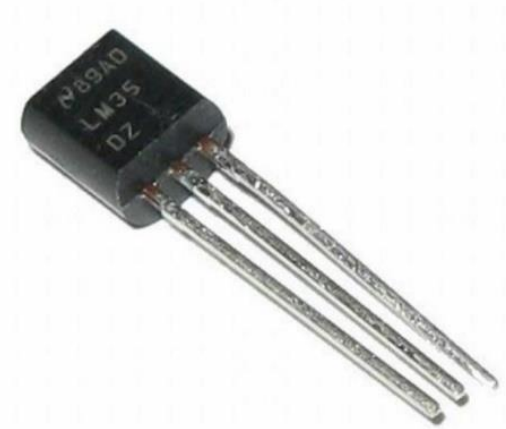

Fig 5.3 Temperature Sensor

This is a LM35 which is a temperature measuring device having an analog output voltage proportional to the temperature. 


\section{c. Sound Sensor}

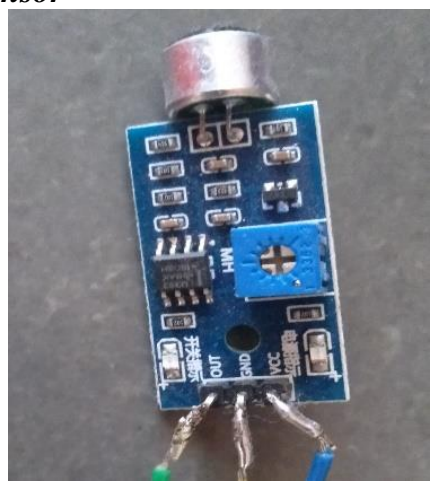

Fig 5.4 Sound Sensor

A Sound sensor is module that detects sound waves through its intensity and converting it to electrical signals.

\section{CONCLUSION}

The system monitors when the tree logging occurs, the sound generated due to axing the tree is sensed by the sound sensor. Also if the tree bends, the buzzer is activated. And if in case forest fires, when the temperature of the surroundings increases its sensed by the temperature of the surroundings increases its sensed by the temperature sensor, through the relay switch the water pump is turned on. Then this generated data is send to the forest officer if any event occurs so that appropriate action can be taken.

\section{REFERENCES}

[1] 'Hameem C Hamza' "Tree Theft Control System” 2013 Texas Instruments India Educators Conference.

[2] 'Ghousia Sultana B' "IOT Based Anti-Poaching Alarm System for Trees in Forest using Wireless Sensor Network” Volume 9, Special Issue No. 3, May 2018.

[3] 'Subhashini A' "Smuggling preventions system for trees in forest using IOT" Chennai International journal of scientific research and innovations IX (2018) 15-22.

[4] 'Mr V. Narasimman Asst.Prof" "Design of a WSN node for forest trees against poaching”.

[5] 'B S Sudha Yogitha' "Forest monitoring system using Wireless Sensor Network" Volume 4, Issue 4 April-2018.

[6] 'Mr Rohan Solarpurkar' "Real Time Forest Anti-Smuggling Monitoring System based on IOT using GSM" International Journal for Research in Engineering Application \& Management (IJREAM) ISSN: 2454-9150 Special Issue- ICSGUPSTM 2018.

[7] 'Prof. Mhaske D.A' "Anti-smuggling System for Trees in Forest using Flex Sensor with Gsm \& Zigbee Network" International Journal of Advanced Research in Computer and Communication Engineering Vol. 5, Issue 4, April 2016.

[8] 'Narhari R. Kotkar M.E (ESD AND VLSI)' "Anti-Smuggling System for Trees in Forest using Flex Sensor and Zigbee" International Journal of Advanced Research in Computer Engineering \& Technology (IJARCET) Volume 3, Issue 9, September 2014.

[9] 'B S Sudha' "Forest Monitoring System Using Wireless Sensor Network”. E-ISSN: 2454-8006 Volume 4, Issue 4 April-2018.

[10] 'Ankita Dalvi' "Undetected Detective to protect the Forest Trees Against Poaching Using WSN Technology” Vol. 3, No.6, 2018.

[11] 'Smita Gaikwad' "Design WSN Node for Protection of Forest Trees Against Poaching based on Zigbee". 